\title{
SEROPREVALENCE OF TOXOPLASMOSIS IN WOMEN IN MYMENSINGH AND RANGPUR IN BANGLADESH: A HOSPITAL SURVEY
}

\author{
U. H. Margia, N. Begum, M. S. Hossain*, A. R. Dey and M. Z. Alam
}

Department of Parasitology, Bangladesh Agricultural University, Mymensingh, Bangladesh.

\begin{abstract}
Toxoplasmosis is a great zoonotic threat that affects human species specially women. It has got major health significance because it causes abortion in pregnant women. The aim of this study was to determine seroprevalence of toxoplasmosis in women in Mymensingh and Rangpur in Bangladesh and to identify possible risk factors associated with toxoplasmosis. In this study, 87 women of 15 to 45 years old were included. Among 87 women, $74.7 \%(n=65)$ were seronegative and $25.3 \%$ were $(\mathrm{n}=22)$ seropositive for T. gondii IgG and IgM antibodies. However, seroprevalence was higher in women aged between 3145years. Relationship between T.gondii antibody and pregnancy was found significant $(\mathrm{p}<0.05)$. This study also reveals that pregnant women are more susceptible to toxoplasmosis than non-pregnant women. Thusly, regular screening test for toxoplasmosis is necessary for pregnant women in Bangladesh.
\end{abstract}

Keywords: Seroprevalance, toxoplasmosis, women, pregnancy.

\section{INTRODUCTION}

Toxoplasmosis, a protozoan zoonosis of global significance, is caused by an obligate intracellular protozoan parasite, Toxoplasma gondii that affects a wide range of hosts and results into high morbidity and mortality (Dubey, 2010).About a third of the world's human population is estimated to carry Toxoplasma parasite (Ryan and Ray, 2004). Probably all warm-blooded animals including most livestock and humans act as intermediate hosts whereas felines (such as domestic cat) act as definitive hosts. The life cycle of $T$. gondii includes asexual multiplication in various tissues of intermediate hosts and sexual reproduction in the intestine of definitive hosts (Hill and Dubey, 2002).

Congenital toxoplasmosis generally occurs when a woman is newly infected with $T$. gondii during pregnancy. In addition, in immunosuppressed women reactivation of an infection acquired before pregnancy can lead to congenital toxoplasmosis (Dubey, 2010). There is a $20-50 \%$ chance of transmitting $T$. gondii to the foetus during pregnancy (Mombro et al., 2003). Several studies have also suggested that latent toxoplasmosis has detrimental neurological and behavioural effects on humans (McAllister, 2005).

Seroprevalence of toxoplasmosis in human populations varies greatly among countries. Studies during the last three decades have found a wide range of $T$. gondii antibody occurrence in human populations from $0 \%$ to $100 \%$ (Tenteret al. 2000).In Bangladesh, a sero-epidemiological study on toxoplasmosis was performed several times and the seroprevalence varies from $11.18 \%$ (Samad et al., 1997) to $38.5 \%$ (Ashrafunnessa et al., 1998) among pregnant women. Also, Ashrafunnessa et al. (1998) reported that seroprevalence gradually increased with age and parity.

Numerous serological procedures are available for the detection of IgG and IgM antibodies including SabinFeldman dye test (DT), indirect haemagglutination assay (IHA), indirect fluorescent antibody assay (IFA), modified agglutination test (MAT), latex agglutination test (LAT), enzyme-linked immunosorbent assay (ELISA), and complement fixation test (CFT) (Pal, 2007). Of these, IFA, ELISA, and MAT have been modified to detect IgM antibodies (Dubey, 2010). The aim of this study was, therefore, to determine the seroprevalence and risk factors of T. gondii in women of Mymensingh and Rangpur district, Bangladesh.

\section{MATERIALS AND METHODS}

The study was conducted in Sadar upazilas of Mymensingh and Rangpur district during January to May 2015. The samples were collected from the women who visited the diagnostic centers for pathological test in Mymensingh and BRAC clinic in Rangpur. A total of 87 blood samples were collected from women aged

*Corresponding e-mail address: shahadat08dvm@gmail.com Copyright $\odot 2017$ Bangladesh Society for Veterinary Medicine 


\section{U. H. Margia and others}

between four groups as 15- 20 years, 21-30 years, 31-45 years and $>45$ years, who attended for the treatment of gyno-obstetrics problem. Forty seven blood samples were collected from Rangpur and forty from Mymensingh. Relevant data like age of the patient, pregnancy status (pregnant or non-pregnant) were collected and recorded sincerely from the register book of those diagnostic centers and clinics. All data gathered was converted to information, compiled and tabulated as per objectives of the study.

Blood specimens from the women were collected into a lavender top collection tube (containing EDTA) and transported to the laboratory of the Department of Parasitology, Bangladesh Agricultural University, Mymensingh. At the laboratory, the serum was separated by centrifugation $(2000 \mathrm{rpm})$ at $4{ }^{\circ} \mathrm{C}$ for 10 minutes and tested for T. gondii specific antibodies using a commercial kit (On Site Toxo IgG/IgM Combo Rapid Test, CTK ${ }^{\circledR}$ Biotech. Inc. USA, R0234C) according to manufacturer's instructions.

Statistical analyses were performed using statistical software package SPSS version 22. Statistical significance was defined as $\mathrm{p}<0.05$.

\section{RESULTS AND DISCUSSION}

In the present study, a total of 87 women were included; among them 47 were from Rangpur and 40 were from Mymensingh. Twenty two (25.3\%) samples were seropositive and sixty five $(74.7 \%)$ were seronegative (Table 1). No significant association $(\mathrm{p}>0.05)$ was found in seroprevalance between Mymensingh and Rangpur districts, Bangladesh (Table 1). Seroprevalence of toxoplasmosis was higher in 31-45 years (30.2\%) than 21-30 years $(23.8 \%), 15-20$ years $(22.2 \%)$ and $>45$ years $(14.3 \%)$. The effect of different age group on the seroprevalence of toxoplasmosis was not significant $(\mathrm{p}>0.05)$ (Table 2). The seroprevalence of toxoplasmosis was higher in pregnant women (39.1\%) than non-pregnant women (9.8\%). Pregnant woman is six times more prone to toxoplasmosis than non-pregnant and their relationship was statistically significant $(\mathrm{p} \leq 0.05)($ Table 3$)$.

Table 1. Seroprevalence of toxoplasmosis in two study areas

\begin{tabular}{lcccccc}
\hline Place & Tested & Positive & Prevalence $(\%)$ & Odd ratio & Chi-square value & P value \\
\hline Rangpur & 47 & 15 & 31.9 & 2.2 & 0.09 NS \\
Mymensingh & 40 & 7 & 17.5 & & \\
Total & 87 & 22 & 25.3 & & \\
\hline
\end{tabular}

$\mathrm{NS}=$ Not significant $(\mathrm{p}>0.05)$

Table 2. Seroprevalence of toxoplasmosis in relation to age of women

\begin{tabular}{|c|c|c|c|c|c|c|c|}
\hline \multirow[t]{2}{*}{ Age(yrs) } & \multirow[t]{2}{*}{ Sera Tested } & \multicolumn{2}{|c|}{ Positive sera } & \multirow[t]{2}{*}{ Total Positive } & \multirow[t]{2}{*}{ Prevalence (\%) } & \multirow[t]{2}{*}{ Chi-square value } & \multirow[t]{2}{*}{$P$ value } \\
\hline & & IgG & IgM & & & & \\
\hline $15-20$ & 9 & 1 & 1 & 2 & 22.2 & 1.52 & $0.74 \mathrm{NS}$ \\
\hline $21-30$ & 21 & 4 & 1 & 5 & 23.8 & & \\
\hline $31-45$ & 43 & 10 & 3 & 13 & 30.2 & & \\
\hline$>45$ & 14 & 1 & 1 & 2 & 14.3 & & \\
\hline Total & 87 & 16 & 6 & 22 & 25.3 & & \\
\hline
\end{tabular}

NS $=$ Not Significant $(\mathrm{p}>0.05)$

Although toxoplasmosis is considered harmless for non-pregnant women, it is potentially harmful during pregnancy, especially at the first trimester (Giannoulis et al., 2008). Seroprevalence of T. gondii varies in different regions of the world (Mandel, 2010). According to Pappas et al.(2009) the seroprevalence in women of child-bearing age in USA, Brazil, Argentina and Colombia was 11.0\%, 7.3-77.5\%, 48.7-53.4\%, and 47.0-63.5\%, respectively, while in Europe it varied between $8.2 \%$ (in Switzerland) and $63.2 \%$ (in Western Pomerania, Germany). In Asia and Oceania, the seroprevalence ranged from 0.8\% (Suwon region, South Korea) to 63.9\% (Babol, Iran) and in Africa, it was between 25.3\% (Burkina Faso) and 75.2\% (Sao Tome and Principe) (Pappas et al., 2009).

In the present study, the seropositivity for anti T.gondii $\operatorname{IgG} \& \operatorname{IgM}$ was $18.4 \%(16 / 87)$ and $6.9 \%(6 / 87)$ respectively whereas $74.7 \%(65 / 87)$ was seronegative. The combined seropositivity for anti $T$. gondii IgG and IgM was found to be $25.3 \%$ (22/87) using Toxo Combo Rapid Test kit. Similar findings were reported by many other scientists in Bangladesh and abroad. Asrafunnessa et al. (1998) reported 110 positive cases of women in Bangladesh carrying IgG antibody among 286 patients and seropositivity was $38.5 \%$.In Iran, Yad et al. (2014) 
performed a prevalence study among pregnant women and found $27.3 \%$ positive cases for toxoplasmosis. Slightly lower IgG rate (15.89\%) was observed by Samad et al. (1993) during experiment among women of Bangladesh with different gyno-obstetrical diseases. Very low rate of toxoplasmosis seropositivity $(3.7 \%)$ was observed by Han et al. (2008) in Korea, who investigated 351 serum samples of pregnant women for anti-T. gondii antibody.

The present study demonstrated a non-significant association between toxoplasmosis and different age groups of women that may be due to small sample size. This finding is in line with the data obtained from study in Saudi Arabia (Al-Qurashi et al., 2001) and in Nigeria (Nasir et al., 2015). The percentage of seropositivity of toxoplasmosis demonstrated a gradual increase with advancing age of the mother, and the percentage was the highest (30.2\%) among women of age-group of 31-45 years in our study (Table 2). This is supported by findings from Yad et al. (2014) who reported the highest prevalence (44\%) among 36-40 year age group and Sarkar et al. 2012 who found highest seropositivity among women of $>30$ yearsin Andhra Pradesh, India. Spalding et al. (2005) also observed a higher prevalence among people aged 20-30 years, and the prevalence of infection was increasing with older age-group. Mittal et al. (1995) opined that the seropositivity of Toxoplasma increases with age which is also supported by Nijem et al. (2009). According to their study, the lowest rate of antibody acquisition occurred in the age-group of 15-20 years. In addition, recent studies like Imam et al. (2016) reported 21.3\% IgG seroprevalence rate among pregnant women in Almadinah. They found increased seropositivity with age; the highest rate of IgG seropositivity was in the age group 35-39 years $(33.3 \%)$, while the youngest and oldest age groups had no positive cases. Similar seropositivity $(27.9 \%)$ to $T$. gondii among pregnant women has been observed by Nijem et al. (2009). On the other hand Nasir et al. (2015) reported highest seroprevalence of $T$. gondii $\operatorname{IgM}$ and IgG antibodies among women in Nigeria within the age group 21-25 years with 46 (76.7\%) and 19 (5.3\%), respectively. Moreover, Jones et al. (2001) described $22.5 \%$ overall seroprevalence in pregnant women where they found $15 \%$ seroprevalence among women aged $15-44$ years.

Wam et al. (2016) revealed 54.5\% seroprevalence of anti- $T$. gondii antibodies among the women of childbearing age. Again, we may have obtained a different result if we considered sampling from only women of child bearing age. However, most of our study population was sampled among those who came for medical check-up at the selected hospitals.

In addition, from this study there is observed significant association between pregnancy status and toxoplasmosis seropositivity $(\mathrm{OR}=6, \mathrm{p}<0.05)$ (Table 3$)$. Toxoplasma antibody among pregnant women is $39.1 \%$ where woman without pregnancy is $9.8 \%$ Toxoplasma seropositive. Zemene et al. (2012) reported $83.6 \%$ (167/201) seroprevalence of T. gondii among the pregnant women; one hundred and sixty three $(81.1 \%)$ of them were IgG seropositive and five $(2.5 \%)$ of them were IgM seropositive, three of the five were positive for both IgM and IgG.A pilot study in Kumaon region of India in 2005 reported 55\% for Toxoplasma IgG antibodies and $20 \%$ for IgM antibodies (Thapliyal et al., 2005). Singh and Pandit (2004) found an overall anti-Toxoplasma IgG seroprevalence of $45 \%$ among pregnant women in New Delhi, India.

Table 3. Seroprevalence of toxoplasmosis in relation to pregnancy of women

\begin{tabular}{lllllll}
\hline Pregnancy status & Tested & Positive & Prevalence $(\%)$ & Odd ratio & Chi-square value & P value \\
\hline Pregnant & 46 & 18 & 39.1 & 6.0 & 8.4 & $* * 0.003$ \\
Non-pregnant & 41 & 04 & 9.8 & & & \\
Total & 87 & 22 & 25.3 & & & \\
\hline
\end{tabular}

**Significant at $(\mathrm{p}<0.05)$

The binding (avidity) of $T$. gondii antigen to specific antibodies can change during the course of infection. During the early (acute) stage of infection, avidity values are low and increase with duration of infection. In this test, sera are run with or without treatment with urea (or other protein denaturing agents) and the difference in titers can be used to determine the recent infection. The test can be used with $\operatorname{IgG}, \operatorname{IgA}$, and $\operatorname{IgE}$ antibodies using different serological procedures, most often ELISA (Dubey, 2010). The sensitivity and specificity of other calculated respectively as $72.9 \%$ and $85.9 \%$ in ELISA, $45.9 \%$ and $96.9 \%$ for LAT as well as $82.9 \%$ and $90.29 \%$ for MAT test (Dubey et al., 1995). 


\section{U. H. Margia and others}

In this study, seroprevalence of toxoplasmosis has been determined in women in Mymensingh and Rangpur districts of Bangladesh by using Toxo Combo Rapid Test kit. This study shows startling seropositivity among pregnant women. This high rate of infection demands the need for preventive measures such as awareness creation about toxoplasmosis; mainly education of pregnant women about the transmission and preventive methods at antenatal care clinics. Hence, further study is needed to carry out with larger sample size and other associated risk factors.

\section{ACKNOWLEDGEMENTS}

Authors express special thanks to the authority of NST scholarship for the financial support to complete this research work successfully.

\section{REFERENCES}

1. Al-Qurashi AR, Ghandour AM, Obeid OE, Al-Mulhim A and Makki SM (2001). Seroepidemiological study of Toxoplasma gondii infection in the human population in the eastern region. Saudi Medical Journal 22: 13-18.

2. Ashrafunnessa, Khatun S, Islam MN and Huq T (1998). Seroprevalence of toxoplasma antibodies among the antenatal population in Bangladesh. Journal of Obstetrics and Gynaecology Research 24: 115-9.

3. Dubey JP, Weigel RM, Siegel AM, Thulliez P, Kitron UD, Mitchell MA, Manelli A, Mateus-Pinilla NE, Shen SK, Kwok OCH and Todd KS (1995). Sources and reservoirs of Toxoplasma gondii infection on swine farms in Illinois. Journal of Parasitology 81:723-729.

4. Dubey JP (2010). Toxoplasmosis of Animals and Humans. CRC Press, Boca Rotan, USA.

5. Giannoulis C, Zournatzi B, Giomisi A, Diza E and Tzafettas I (2008). Toxoplasmosis during pregnancy: a case report and review of the literature, Department of Obstetrics and Gynecology, Aristotle University of Thessaloniki Greece 12: 139-143.

6. Han K, Shin DW, Lee TY and Lee YH (2008). Seroprevalence of Toxoplasma gondii infection and risk factors associated with seropositivity of pregnant women in Korea. Journal of Parasitology 94: 963-965.

7. Hill D and Dubey JP (2002). Toxoplasma gondii: transmission, diagnosis and prevention. Clinical Microbiology and Infectious Diseases 8: 634-640.

8. Imam NFA, Azam EAA, Attia AA (2016). Seroprevalence of Toxoplasma gondii among pregnant women in Almadinah Almunawwarah, KSA. Journal of Taibah University Medical Sciences 11: 255-259.

9. Jones JL, Kruszon-Moran D, Wilson M, McQuillan G, Navin T and McAuley JB (2001). Toxoplasma gondii infection in the United States: seroprevalence and risk factors. American Journal of Epidemiology 154: 357-365.

10. Mandel GL, Bennet JE and Bennett DR (2010). Bennett's principles and practice of infectious diseases. $7^{\text {thedn., }}$ pp. 3495-522. Philadelphia, Churchill Livingstone.

11. McAllister MM (2005). A decade of discoveries in veterinary protozoology changes our concept of "subclinical" toxoplasmosis. Veterinary Parasitology 132: 241- 247.

12. Mittal V, Bhatia R, Singh VK and Sehgal S (1995). Prevalence of toxoplasmosis in Indian women of child bearing age. Indian Journal of Pathology and Microbiology 38: 143-5.

13. Mombro M, Perathoner C, Leone A, Buttafuoco V, Zotti C, Lievre MA and Fabris C (2003). Congenital toxoplasmosis: assessment of risk to newborns in confirmed and uncertain maternal infection. European Journal of Pediatrics 162: 703-706.

14. Nasir IA, Aderinsayo AH, Mele HU and Aliyu MM (2015). Prevalence and associated risk factors of Toxoplasma gondii antibodies among pregnant women attending Maiduguri teaching hospital, Nigeria. Journal of Medical Sciences 15: 147-154.

15. Nijem KI and Amleh SA (2009). Seroprevalence and associated risk factors of toxoplasmosis in pregnant women in Hebron district, Palestine. Eastern Mediterranean Health Journal 15: 1278-1284.

16. Pal M (2007). Zoonoses. $2^{\text {nd }}$ edn., Satyam Publishers, Jaipur, India.

17. Pappas G, Roussos N and Falagas ME (2009). Toxoplasmosis snapshots: global status of Toxoplasma gondii seroprevalence and implications for pregnancy and congenital toxoplasmosis. International Journal of Parasitology 39: $1385-94$.

18. Ryan KJ and Ray CG (2004). Sherris Medical Microbiology. $4^{\text {th }}$ edn., McGraw Hill. New York, pp. 723-7.

19. Samad MA, Dey BC, Chowdhury NS and Akhtar S (1997). Sero-epidemiological studies on Toxoplasma gondii infection in man and animals in Bangladesh. Southeast Asian Journal of Tropical Medicine Public Health 28: 33943. 
20. Samad MA, Rahman KB and Halder AK (1993). Seroprevalence of Toxoplasma gondii in domestic ruminants in Bangladesh. Veterinary Parasitology 47: 157-9.

21. Sarkar MD, Anuradha B, Sharma N and Roy RN (2012). Seropositivity of toxoplasmosis in antenatal women with bad obstetric history in a tertiary-care hospital of Andhra Pradesh, India. Journal of Health, Population and Nutrition 30: 87-92.

22. Singh S and Pandit AJ (2004). Incidence and prevalence of toxoplasmosis in Indian pregnant women: a prospective study. American Journal of Reproductive Immunology 52: 276-83.

23. Spalding SM, Amendoeira MR, Klein CH and Ribeiro LC (2005). Serological screening and toxoplasmosis exposure factors among pregnant women in south of Brazil. Revista da SociedadeBrasileira de Medicina Tropical 38: $173-7$.

24. TenterAM, Heckeroth AR and Weiss LM (2000). Toxoplasma gondii: from animals to humans. International Journal for Parasitology 30: 1217-58.

25. Thapliyal N, Shukla PK, Kumar B, Upadhyay S and Jain G (2005). TORCH infection in women with bad obstetric history- a pilot study in Kumaon region. Indian Journal of Pathology and Microbiology 48: 551-3.

26. Wam EC, Sama LF, Ali IM, Ebile WA, Aghangu LA and Tume CB (2016). Seroprevalence of Toxoplasma gondiiIgG and IgM antibodies and associated risk factors in women of child-bearing age in Njinikom, NW Cameroon. BMC Research Notes 9: 406.

27. YadYad MJ, Jomehzadeh N, JafarSameri M and Noorshahi N (2014). Seroprevalence of anti-Toxoplasma gondii antibodies among pregnant woman in South Khuzestan, Iran. Jundishapur Journal of Microbiology 7: e9998.

28. Zemene E, Yewhalaw D, Abera, S, Belay T, Samuel A and Zeynudin A (2012). Seroprevalence of Toxoplasma gondiiand associated risk factors among pregnant women in Jimma town, Southwestern Ethiopia. BMC Infectious Diseases 12: 337. 